\title{
The morphologies and compositions of depleted uranium particles from an environmental case-study
}

\author{
N. S. Lloyd ${ }^{1, *}$, J. F. W. Mosselmans ${ }^{2}$, R. R. Parrish ${ }^{1,3}$, S. R. N. Chenery ${ }^{4}$, S. V. Hainsworth ${ }^{5}$ \\ AND S. J. KEMP ${ }^{4}$ \\ ${ }^{1}$ Department of Geology, University of Leicester, University Road, Leicester LE1 7RH, UK \\ ${ }^{2}$ Diamond Light Source Ltd., Diamond House, Chilton, Didcot DE0 11OX, UK \\ ${ }^{3}$ NIGL, Kingsley Dunham Centre, Keyworth, Nottingham NG12 5GG, UK \\ ${ }^{4}$ British Geological Survey, Kingsley Dunham Centre, Keyworth, Nottingham NG12 5GG, UK \\ ${ }^{5}$ Department of Engineering, University of Leicester, University Road, Leicester LE1 7RH, UK
}

[Received 15 March 2009; Accepted 21 July 2009]

\section{ABSTRACT}

Uraniferous particles from contaminated environmental samples were analysed by scanning electron microscopy with energy dispersive X-ray analysis (SEM-EDXA) and microfocus extended X-ray absorption fine structure ( $\mu$ EXAFS) spectroscopy. The particles of interest are uranium oxides, which were released into the environment by the combustion of scrap depleted uranium (DU) metal at a factory in Colonie, New York, USA. Most of the identified particles appear to have primary, 'as emitted' morphologies; some have evidence of minor dissolution, including corrosion pitting. Polycrystalline and often hollow microscopic spheres were identified, which are similar to particles produced by DU munitions impacting armoured targets. They are attributed to the autothermic oxidation of melt droplets. The compositions of the analysed spheres are dominated by $\mathrm{UO}_{2+x}$ with variable amounts of $\mathrm{U}_{3} \mathrm{O}_{8}$, two of the least soluble and least bioaccessible phases of $\mathrm{U}$. These particles, collected from dusts and soils, have survived more than $25 \mathrm{y}$ in the terrestrial environment. This study further supports the case for using Colonie as an analogue for battlefield DU contamination.

KeYwords: depleted uranium, DU, uranium oxide, particles, morphology, EXAFS, SEM, environmental, mineralogy, bioaccessibility.

\section{Introduction}

\section{Case study}

NATIONAL LeAD INDUSTRIES (NLI) operated a plant in Colonie (New York, USA), from 1958-1984. The plant processed $\mathrm{U}$ metals (DU and some enriched uranium) and manufactured kinetic energy penetrators, counterweights and radiation shielding from depleted uranium (DU). Uranium tetrafluoride $\left(\mathrm{UF}_{4}\right)$ was reduced to metal by $\mathrm{Mg}$. Scrap metal was combusted in a furnace prior to disposal as uranium oxide, which resulted in emissions of uranium oxide particulates to the environment (ATSDR, 2004). Contamination of

*E-mail: ns13@alumni.leicester.ac.uk

DOI: 10.1180/minmag.2009.073.3.495 the suburban environment surrounding the NLI plant by DU is evident in air filters, surface soils, reservoir sediments, dusts and the urine of former employees and some residents (Dietz, 1980; Jeter and Eagleson, 1980; Arnason and Fletcher, 2003; Lo et al., 2006; Lloyd et al., 2008; Parrish et al., 2008; Lloyd et al., 2009).

From the soil concentration data of Jeter and Eagleson (1980), we estimated that at least 3.4 tonnes of $\mathrm{U}$ was deposited within $1 \mathrm{~km}^{2}$ of the NLI plant (Parrish et al., 2008) and that the distribution of contamination was controlled by prevailing winds (Lloyd et al., 2008). Soils and dusts from the vicinity of the NLI plant were contaminated by the aerial deposition of anthropogenic U particulates; the vast majority of this contamination was deposited prior to 1980 . From 
a sample of 115 particles, individually analysed by laser ablation-multicollector- inductively coupled plasma-mass spectrometry (LA-MCICP-MS), all were found to have DU isotope ratios, $n^{235} \mathrm{U} / n^{238} \mathrm{U}=(1.5-2.4) \times 10^{-3}$ (Lloyd et al., 2009). The aim of this research is to define the present forms of contaminant $U$ and to relate these to emission processes and their subsequent exposure in the terrestrial environment.

The primary concern for this radioactive and toxic material is inhalation exposure. The lung is the radiological 'target' for the less soluble $\mathrm{U}$ compounds (e.g. $\mathrm{UO}_{2}$ and $\mathrm{U}_{3} \mathrm{O}_{8}$ ), the bones and kidney (also toxicological) for the more soluble compounds (e.g. $\mathrm{UO}_{3}$ ) which enter the bloodstream via the lungs (Eidson, 1994). The Royal Society concluded that for most battlefield DU exposure scenarios, the human-health risks were low and affect a small number of people (The Royal Society, 2001, 2002). The ATSDR found that the inhalation of DU emissions from the NLI plant could have increased the risk of health effects for Colonie residents (ATSDR, 2004).

\section{DU particulates from munitions}

High velocity DU metal projectiles, which are typically an alloy of DU and 0.75 wt.\% Ti, are used as armour-piercing munitions by British and American tanks and American A-10 aircraft. These DU 'kinetic energy penetrators' pierce heavy armour efficiently. Upon impact, the metal combusts and a fraction is dispersed as uranium oxide particulates (The Royal Society, 2001; Bleise et al., 2003).

We aim to use the Colonie case-study as an analogue for the contamination from munitions use and to investigate the environmental fate of this controversial contaminant. The Colonie site has a relatively large contamination footprint $\left(\sim 100 \mathrm{~km}^{2}\right)$; the area is readily accessible and the contamination has been in the environment prior to 1984 (cf. the first reported deployment of munitions was during the 1991 Gulf War). However, the Colonie particulates were generated in a furnace that probably did not achieve the high pressures and temperatures (up to $3639 \mathrm{~K}$, Patrick and Cornette, 1978) of munitions impacting armoured targets and the particles may therefore differ in composition and morphology. Their combustion may have been less heterogeneous than for munitions, which undergo an initial high energy impact and interaction with armour materials, followed by combustion or low-temp- erature oxidation of fragments that perforate through the target, resulting in highly heterogeneous particle morphologies (Krupka et al., 2009). This study addresses one of the recommendations of The Royal Society (2002) that information should be obtained on the bioavailability of DU particles. Colonie has also been proposed for health studies (e.g. Parrish et al., 2008) and further information on the nature of the contamination is therefore desirable.

A brief review of the literature pertaining to the oxidation states of anthropogenic uranium oxide particles from environmental samples and from DU munitions testing is presented in Table 1 . We focus on the combustive products, rather than the corrosion products of uranium. However, the origin of environmental particles is not always clear from the literature. Although each individual study is limited by small sample size, particles from environmental samples tend to be dominated by $\mathrm{UO}_{2}$ and mixed $\mathrm{UO}_{2}-\mathrm{U}_{3} \mathrm{O}_{8}$, but also include $\mathrm{U}_{3} \mathrm{O}_{8}$ and, rarely, uranyl species $\left(\mathrm{U}^{6+}\right)$. The Chernobyl particles revealed heterogeneity between rim and core, attributed to formation processes.

Aerosols from DU test-firing and combustion experiments appear primarily to be $\mathrm{U}_{3} \mathrm{O}_{8}$. However, these studies analysed bulk samples using X-ray diffraction (XRD) techniques. In XRD, peak overlaps from $\mathrm{U}_{3} \mathrm{O}_{8}$ and $\mathrm{U}_{4} \mathrm{O}_{9}$ can mask minor amounts of $\mathrm{UO}_{3}$ and $\mathrm{UO}_{2}$ respectively (Krupka et al., 2009). Microfocus $\mathrm{X}$-ray absorption techniques ( $\mu \mathrm{XAS}$ ) can analyse individual particles and parts thereof, but fine particulates represented in the bulk samples are less likely to be located for analysis, potentially biasing the results. XAS is capable of resolving $\mathrm{U}_{3} \mathrm{O}_{8}$ from $\mathrm{UO}_{3}$.

The significance of $U$ speciation is discussed in the next section. It is an aim of this study to determine the $U$ speciation of particles from Colonie environmental samples and to resolve heterogeneity where possible. We used $\mu$ XAS techniques, including: X-ray absorption near edge spectroscopy (XANES), which is sensitive to oxidation state; and extended X-ray absorption fine structure (EXAFS) spectroscopy, which is a probe of local atomic structure (Koningsberger and Prins, 1988).

\section{The environmental behaviour of uranium oxides}

Uraninite (hyperstoichiometric cubic/tetragonal phase $\mathrm{UO}_{2}$ or $\mathrm{UO}_{2+x}$, where $x<0.33$ ) and other $\mathrm{U}^{4+}$ species have extremely low solubility under reducing conditions (Langmuir, 1997). In 
MORPHOLOGIES AND COMPOSITIONS OF DU PARTICLES

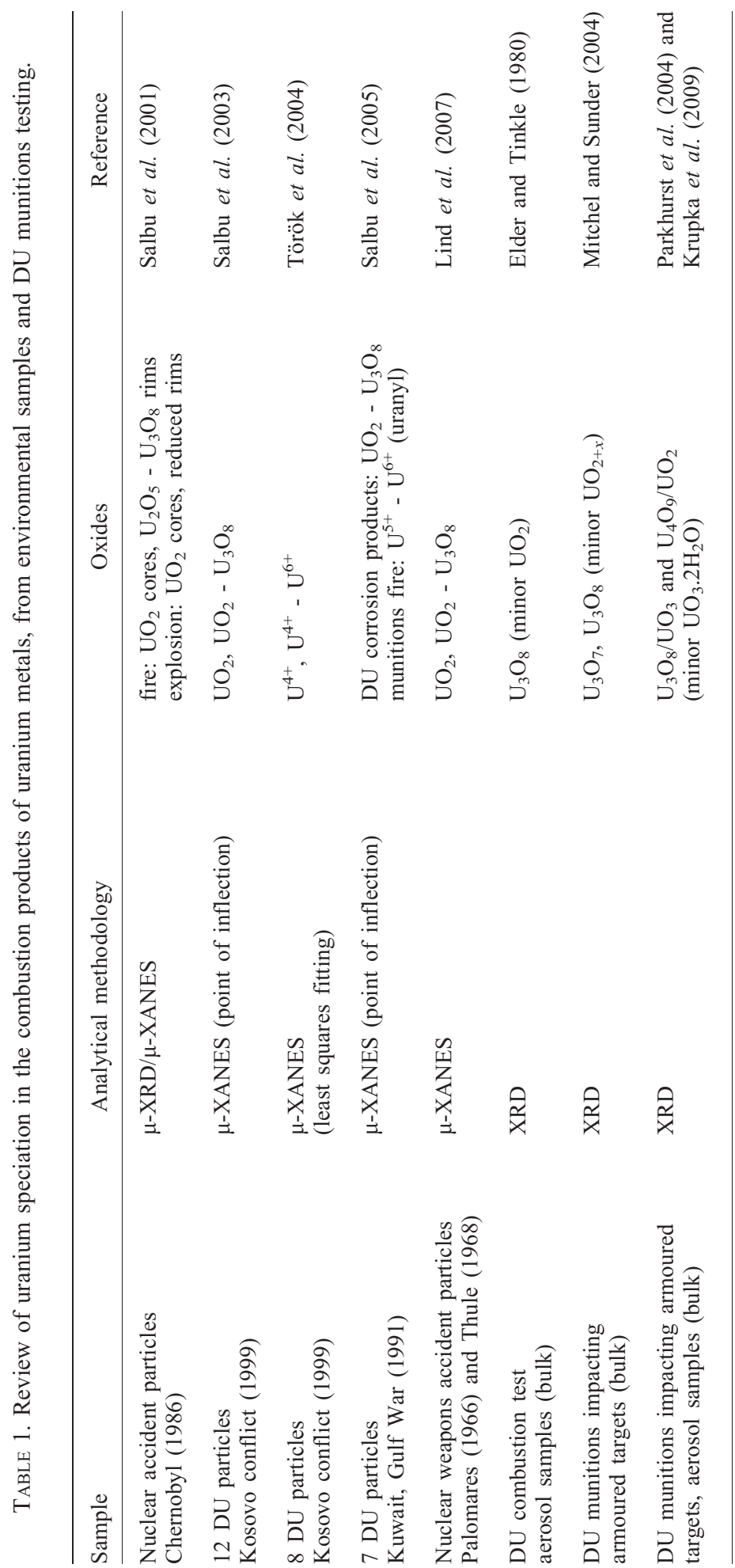


oxidizing surface and ground waters, dissolution of $\mathrm{UO}_{2}$ proceeds by an oxidation step, forming the significantly more soluble $\mathrm{U}^{6+}$ species, e.g. $\mathrm{UO}_{2(\mathrm{aq})}^{2+}$ and uranyl complexes (Wang and Katayama, 1982; Torrero et al., 1998; Roth and Jonsson, 2008). The differences in solubility between the $\mathrm{U}^{4+}$ and $\mathrm{U}^{6+}$ species are apparent in the absorption rate classification of uranium oxides for dose assessment from inhalation exposure. Ansoborlo et al. (2002) classified $\mathrm{UO}_{2}$ and $\mathrm{U}_{3} \mathrm{O}_{8}$ as slow, Type $\mathrm{S}$ (ICRP, 1995), with dissolution half-lives in simulated lung fluid of at least 700 days, $\mathrm{U}_{3} \mathrm{O}_{8}$ dissolving more rapidly than $\mathrm{UO}_{2}$. In contrast, $\mathrm{UO}_{3}$ has a dissolution half-life of less than 10 days and is classified as fast, Type F.

The initial rapid dissolution rates seen in in vitro lung fluid experiments (e.g. Mitchel and Sunder, 2004; Parkhurst et al., 2004; Guilmette and Cheng, 2009), may be accounted for by mixtures of particle sizes, morphologies and oxide phases including surface products. Depleted uranium aerosols generated from munitions impacting armoured targets had variable and complex solubility in simulated extracellular fluids, with dissolution behaviour similar to either Type M (intermediate rate) or Type S (Parkhurst et al., 2004; Guilmette and Cheng, 2009). Thus, the degree of oxidation and the process of oxidation are significant to both the environmental fate and bioaccessibility of uranium oxide contamination. It should be noted however, that these experiments do not simulate the action of macrophage lysosomes, which convert $\mathrm{U}_{3} \mathrm{O}_{8}$ to insoluble phosphate phases in vivo (Berry et al., 1997).

Stoichiometric $\mathrm{UO}_{2}$ oxidizes readily in air and fine powders can behave pyrophorically. At environmental temperatures, thin films (a few $\mathrm{nm}$ thick) of higher oxides form on $\mathrm{UO}_{2}$ in air; $\mathrm{UO}_{3}$ is thermodynamically favoured, but this reaction is limited by oxygen ion diffusion (McEachern and Taylor, 1998). Surface uranyl $\left(\mathrm{UO}_{2}^{2+}\right)$ ions are observed from the oxidation of hyperstoichiometric $\mathrm{UO}_{2}\left(\mathrm{UO}_{2+x}\right)$ in moist air at $353 \mathrm{~K}$ (Schueneman et al., 2003). Polycrystalline $\mathrm{UO}_{2.05}$ has also been observed to oxidize partially, over $15 \mathrm{y}$ in ambient conditions, to $\mathrm{UO}_{3} \cdot 2 \mathrm{H}_{2} \mathrm{O}$ (metaschoepite) (Wadsten, 1977).

The uranium dioxide fluorite-type cubic lattice and its derivatives $\left(\mathrm{UO}_{2+x}\right)$ accommodate interstitial oxygen atoms in the range $\mathrm{UO}_{2}-\mathrm{UO}_{2.33} /$ $\beta-\mathrm{U}_{3} \mathrm{O}_{7}$; higher oxides $\left(\mathrm{U}_{3} \mathrm{O}_{8}-\mathrm{UO}_{3}\right)$ adopt an orthorhombic lattice with lower density (Allen and Tempest, 1986). At elevated temperatures, bulk oxidation of $\mathrm{UO}_{2+x}$ can occur, including
$\mathrm{U}_{3} \mathrm{O}_{8}$ formation at temperatures greater than about $523 \mathrm{~K}$ (McEachern and Taylor, 1998). Uraninite $\left(\mathrm{UO}_{2+x}\right)$ is the most common $\mathrm{U}$ ore mineral, but re-crystallization to orthorhombic $\mathrm{U}_{3} \mathrm{O}_{8}$ has never been reported in nature, demonstrating the environmental stability of this mineral (Finch and Ewing, 1992). Thus, $\mathrm{U}_{3} \mathrm{O}_{8}$ and higher oxides will not be formed in significant quantities from $\mathrm{UO}_{2+x}$ in ambient air, but could have formed in the NLI conversion furnace. The rate of $\mathrm{U}_{3} \mathrm{O}_{8}$ formation on $\mathrm{UO}_{2}$ powders is slow, forming as a major product at $533 \mathrm{~K}$ in around $25 \mathrm{~h}$ (references in McEachern and Taylor, 1998).

Anderson et al. (1955) compared the oxidized thin surface films on $\mathrm{UO}_{2}$ powders to those forming at low temperatures on other metals. Passive surface oxide films (nm thick) form on metals such as $\mathrm{Al}$, protecting the bulk metal from further oxidation; however these films are susceptible to corrosion pitting. This process is autocatalytic in the presence of water and a strong anion, e.g. $\mathrm{Cl}^{-}$(Frankel, 1998). This process might therefore promote oxidation and dissolution of uranium dioxide.

\section{Methodology}

\section{Samples}

Particles of interest were concentrated from contaminated dust and soil samples collected from the vicinity of the former NLI site in Colonie. The dust samples for $\mu$ XAS were collected from a covered site at ground level, which has accumulated windblown material over several decades (it is possible that these samples were occasionally saturated by rainwater). This site afforded a large quantity of relatively concentrated material $\left(385 \pm 33 \mu \mathrm{g} \mathrm{g}^{-1} \mathrm{U}\right.$, cf. natural $U$ concentrations in Colonie soils at $\sim 1 \mu \mathrm{g} \mathrm{g}^{-1}$ ). Other dry dust samples from residential properties were collected by brushing or dry wiping material into clean polystyrene tubes. Soil samples were collected by hand-auger from the surface to a depth of $15 \mathrm{~cm}$.

\section{Sample preparation}

Sample preparation methodology is detailed in Lloyd et al. (2009) and summarized here. Soil samples were dried at between 40 and $60^{\circ} \mathrm{C}$ and sieved to $<2 \mathrm{~mm}$. Dense grains and particulates, including uranium oxides greater than approximately $20 \mu \mathrm{m}$ diameter, were concentrated by dense liquid separation (using di-iodomethane, 
$D=3.3 \mathrm{~g} \mathrm{~cm}^{-3}$ ). Magnetic minerals, iron oxides and some zircons were removed by magnetic barrier separation (Frantz LB-1). This methodology is rapid when compared to fission-track or sample splitting techniques.

For electron microscopy, both raw sample and concentrates were mounted by dabbing the surface of a carbon adhesive disc onto the sample material and lightly tapping to remove loose grains.

For XAS, an individual particle approach was required. From the dense concentrates, particles with anthropogenic appearance, including spherical particles, typically $20-80 \mu \mathrm{m}$ in diameter and with a glassy or metallic lustre, were picked under an optical microscope using fine tweezers. Larger, frosted and rounded quartz grains had previously been removed by density separation. The remaining natural dense minerals grains were typically sub-angular, with irregular or crystalline habit (including detrital zircons, garnet, rutile, etc.). Picking was performed in a Petri dish with the grains submerged in ethanol, the grains of interest were transferred by pipette to a clean dish and the ethanol evaporated.

The particles of interest were then transferred by tweezers to a low-tack adhesive mount. For this we used, as a substrate, Glue Dot Repo ${ }^{(\mathbb{1}}$ (Keighley, UK), a proprietary craft material that appears clean and from which particles can easily be removed without visible residue. The mounts were then examined by SEM-EDXA. Uraniferous grains were identified by the presence of $\mathrm{U}-M \alpha$ $\mathrm{X}$-ray peaks.

Of several thousand picked particles, fewer than one in ten comprised U, with most of the rest comprising $\mathrm{Pb}, \mathrm{Sn}$ and/or silica. The uraniferous particles are typically opaque, dark grey with a dull metallic lustre; they tend to be fragile and some are hollow shells. The uraniferous particles were then transferred, embedded in epoxy resin and polished to reveal their cross-sections. Images from the sample preparation steps can be found in Appendix 2.7. Appendices are deposited with the Principal Editor of Mineralogical Magazine and are available from: www.minersoc.org/pages/ e_journals/dep_mat_mm.html.

\section{X-ray absorption spectroscopy (XAS)}

\section{Standards}

We are not aware of any commercially available stoichiometric uranium oxide standard and it appears that many chemical companies have stopped stocking these compounds. Three uranium oxide compounds were purchased from IBI Labs (Boca Raton, Florida, USA): $\mathrm{UO}_{2}, \mathrm{U}_{3} \mathrm{O}_{8}$ and $\gamma-\mathrm{UO}_{3}$.

$\mathrm{XRD}$ revealed that none of these powders were pure. The $\mathrm{U}_{3} \mathrm{O}_{8}$ was mixed with $\mathrm{UO}_{3} \cdot 2 \mathrm{H}_{2} \mathrm{O}$ (metaschoepite), $\mathrm{UO}_{3} \cdot 0.8 \mathrm{H}_{2} \mathrm{O}$ (dehydrated schoepite) and $\mathrm{Ag}_{2} \mathrm{~S}$ (acanthite), but we were able to pick black $\mathrm{U}_{3} \mathrm{O}_{8}$ grains from this material. Contamination of $\mathrm{UO}_{2}$ by $\mathrm{UO}_{3} \cdot 0.8 \mathrm{H}_{2} \mathrm{O}$ (dehydrated schoepite) was insignificant. The $\gamma-\mathrm{UO}_{3}$ was mixed with a significant quantity of another $\mathrm{U}^{6+}$ compound, $\mathrm{UO}_{3} \cdot 0.8 \mathrm{H}_{2} \mathrm{O}$. Further information on the XRD analyses can be found in Appendix 1.5. The compounds were ground in an agate pestle and mortar; approximately $20 \mathrm{mg} \mathrm{U}$ equivalent were mixed with boron nitride (BN) powder and compressed into $8 \mathrm{~mm}$ diameter pellets.

\section{Experimental}

XAS was performed at the microfocus spectroscopy beamline I1 8 of The Diamond Light Source (Harwell, UK), a third generation electron synchrotron (3 GeV, $250 \mathrm{~mA}$ ), described in Mosselmans et al. (2008). The X-ray beam diameter at the sample position measured $3.5 \mu \mathrm{m}$.

The experimental set-up is shown in Fig. 1. Standards were measured in transmission mode and the samples by fluorescence (measured perpendicular to the excitation beam). Similar information can be derived from the two analysis modes. The standards were measured once each, twice for $\mathrm{U}_{3} \mathrm{O}_{8}$ (with similar results). The spectra are supported by theoretical modelling. For each sample particle, three or four separate spot analyses were measured in duplicate using the same beam position for each duplicate measurement. No difference was apparent between duplicate spectra that could be attributed to oxidation.

X-ray absorption spectra were collected using a $\mathrm{Si}(111)$ double crystal monochromator scanned over the range $17.00-17.35 \mathrm{keV}$, crossing the $\mathrm{U}-L_{\mathrm{III}}$ absorption edge in $0.5 \mathrm{eV}$ steps, counting each step for $1 \mathrm{~s}$, increasing to $2 \mathrm{eV}$ steps and $4 \mathrm{~s}$ for higher energies. In the analyses of the spectra, the edge positions were calculated as the point of inflection (peak of first derivative of $\mu(\mathrm{E})$, after low-pass Fourier transform filter).

Microfocus extended X-ray absorption fine structure $(\mu \mathrm{EXAFS}), \chi(\mathrm{k})$ spectra were isolated using PySpline (Tenderholt et al., 2007), by least squares fitting of quadratic splines and optimization of the Fourier transform (radial function). Extended $\mathrm{X}$-ray absorption fine structure modelling from 


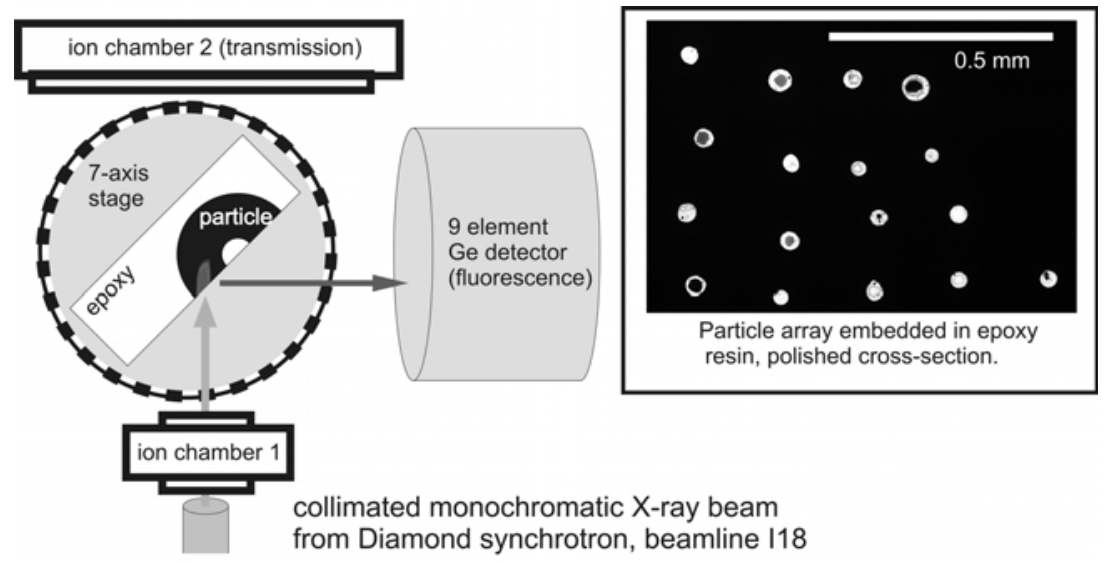

FIG. 1. Diagram of the experimental set-up for XAS, standards were measured in transmission mode, samples by fluorescence. SEM image of particle array (right).

crystallographic data was performed using DL_EXCURV (Tomic et al., 2005), achieving reasonable fits to the standard spectra (to $\mathrm{k}=$ $9.5 \AA^{-1}$ ) from 3 scattering shells $\left(2\right.$ for $\mathrm{UO}_{3}$ ), including multiple scattering paths (see Fig. 2).

\section{Scanning electron microscopy (SEM-EDXA)}

Two SEMs were used to investigate raw dust samples, dense concentrates from dusts and soils and picked uranium oxide spheres: (1) a Hitachi S-3600N 'environmental' SEM fitted with an
Oxford Instruments Inca X-sight; and (2) an FEI Sirion 200 field emission SEM fitted with a Princeton Gamma Tech. 'Spirit' X-ray analyser. Energy dispersive X-ray spectrometers cannot quantify oxygen and it was therefore not possible to distinguish the different uranium oxides phases. The environmental SEM, operating at $P=20 \mathrm{~Pa}$, allowed uncoated specimens to be imaged using backscattered electron (BSE) detectors; this mode facilitates detection of heavy elements such as $U$. Carbon coating and high vacuum were used for secondary electron (SE) imaging. Accelerating

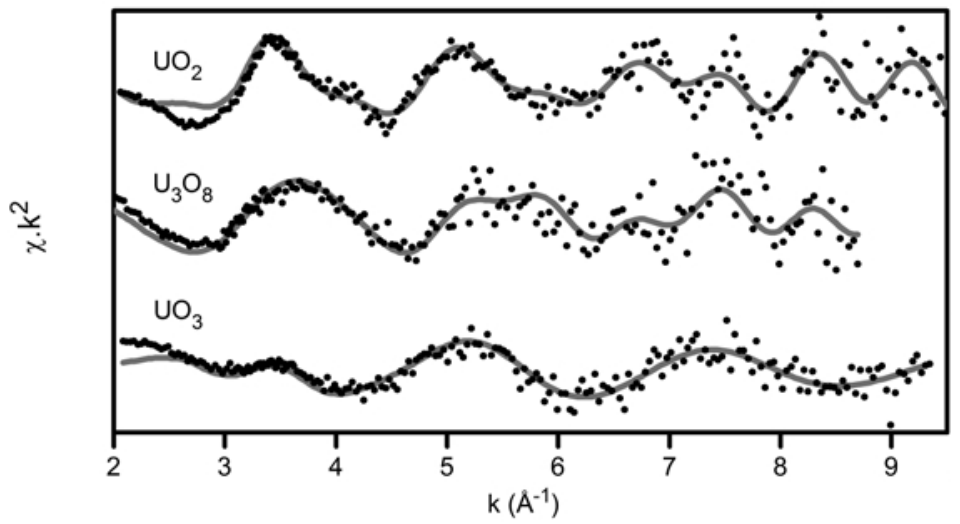

FIG. 2. EXAFS spectra from standards: experimental data points (dots) and theoretical models (lines). The models achieve reasonable fits from 3 scattering shells $\left(2\right.$ for $\left.\mathrm{UO}_{3}\right)$ and are based on crystallographic data from ICSD (Fletcher et al., 1996). The second dominant oscillations, peaking in the region $\mathrm{k}=3-4 \AA^{-1}$, are distinct for each standard. For $\mathrm{UO}_{2}$, contributions from the first oxygen and uranium scattering shells create a distinctive asymmetric second peak in this region. It should be noted that the amplitude of EXAFS in measured absorption spectra decreases with $\mathrm{k}$ value. Therefore, they are amplified by $\mathrm{k}^{2}$, but noise becomes an inherent issue at higher $\mathrm{k}$ values. 
voltages of $15-30 \mathrm{kV}$ were used; lower accelerating voltages improve spatial resolution, but higher accelerating voltage improves X-ray detection.

\section{Results}

SEM-EDXA

\section{Composition}

The majority of the EDXA spectra from the uraniferous particles analysed were dominated by the $\mathrm{U}-M \alpha$ peak $(3.17 \mathrm{keV})$, an $\mathrm{O}-K$ peak and also a $\mathrm{C}-K$ peak generated from the mounting substrates. This was almost exclusively true of 'clean' areas from uraniferous spheres. Aluminium and $\mathrm{Si}$ peaks were commonly associated with surface-adhering clays, appearing as dark cloudy regions in BSE mode and translucent platy regions in SE mode. Other common elements, frequently identified as surface contamination, included $\mathrm{Mg}, \mathrm{Fe}, \mathrm{Na}$, $\mathrm{Mn}, \mathrm{Ca}, \mathrm{K}, \mathrm{Cl}, \mathrm{S}$, and less commonly $\mathrm{Cu}$ and $\mathrm{P}$. Peaks from Ti were, on occasions, also identified; however, the Ti concentration in the DU alloy, at $\sim 0.75 \mathrm{wt} . \%$, is close to the limit of detection for this method. Molybdenum and $\mathrm{Nb}$ were not detected, although these elements were used in some DU alloys instead of $\mathrm{Ti}$ in an attempt to improve mechanical properties and corrosion resistance (Hopson et al., 1973).

\section{Size}

Uraniferous particles from raw samples were identified with geometric diameters in the range 0.5-150 $\mu \mathrm{m}$ (approximate unimodal log-normal particle size distribution, coarse particle sizerange; see Appendix 2.8 for histogram). The threshold for respirable particulate matter $\left(\mathrm{PM}_{2.5}\right.$, particulate matter less than $2.5 \mu \mathrm{m}$ aerodynamic equivalent diameter) is $0.8 \mu \mathrm{m}$ for $\mathrm{UO}_{2}(D=$ $\left.10.96 \mathrm{~g} \mathrm{~cm}^{-3}\right)$. Particle size distributions were not accurately determined, because location by SEM becomes increasingly difficult for smaller particulates. Particles of interest are scarce in raw samples and concentrates are inherently biased because fine particulates $<\sim 20 \mu \mathrm{m}$ diameter do not settle readily in dense liquids. Importantly, it was noted that the particles are often brittle and easily broken into smaller fragments, some of which would then be inhalable.

\section{Morphology}

Figure 3 presents a selection of 18 SEM micrographs of uraniferous particles identified from environmental dust and soil samples; their morphologies are described in the following text. Additional micrographs, including all of the identified uraniferous spheres, with the crosssections of those analysed by XAS, are presented in Appendix 2.

Figure $3 a$ shows a well preserved uranium oxide sphere from a dust sample; the surface is split and there is some evidence of minor pitting on the surface (Fig. 3b). Based on their geometry, we interpret the cavities in the surface of spheres Fig. $3 c, d$ (both from soil samples) as possible evidence of corrosion pitting. Corrosion pitting is a process to which uranium oxides, for reasons previously discussed, are likely to be susceptible in the environment. We also considered the etching of alpha recoil damage from ${ }^{238} \mathrm{U}$ decay and although the distribution of these cavities is compatible with this idea, $\mathrm{UO}_{2}$ recovers from this type of damage (Matzke, 1999). The amount of corrosion from these and other spheres appears minor (a few percent).

Some of the spheres have tails, consistent with mid-air solidification from a melt. Many are hollow (Fig. 3f,g), or include cavities (see Appendix 2.3), the formation of which is discussed in the following sub-section. The interior of the cavity shown in Fig. $3 g$ contains square tabular crystals, but the spheres more typically comprise $1-2 \mu \mathrm{m}$ diameter equiaxial crystals as in Fig. $3 d$, but sometimes as coarse as $12 \mu \mathrm{m}$ in diameter as is shown in Fig. $3 h$. Some of the cross-sections reveal coarser crystals towards their centres (see Appendix 2.3).

Patrick and Cornette (1978) observed interconnecting concave plates across the surface of uranium oxide spheres from DU munitions impacting armoured targets and interpreted their formation as melt-freezing from multiple sites across their surface. Similar platy surfaces are seen in Fig. $3 h, i$. The sutured platy texture in Fig. $3 h$ is strikingly similar to that presented in fig. $7 b$ of Krupka et al. (2009), but the size of particle in Fig. $3 h$ is $>5$ times larger.

Some of the non-spherical particles are comprised of agglomerated 1-2 $\mu \mathrm{m}$ diameter uraniferous grains. Triple junctions between these are shown in Fig. 3j. This texture could have been created by compression of aggregates in the furnace grate, under the weight of other material. Alternatively, the texture may have been formed by powder metallurgy type processes at NLI, but it is distinct from sintered $\mathrm{UO}_{2}$ fuel (e.g. in Kashparov et al., 2004). Non-compacted 


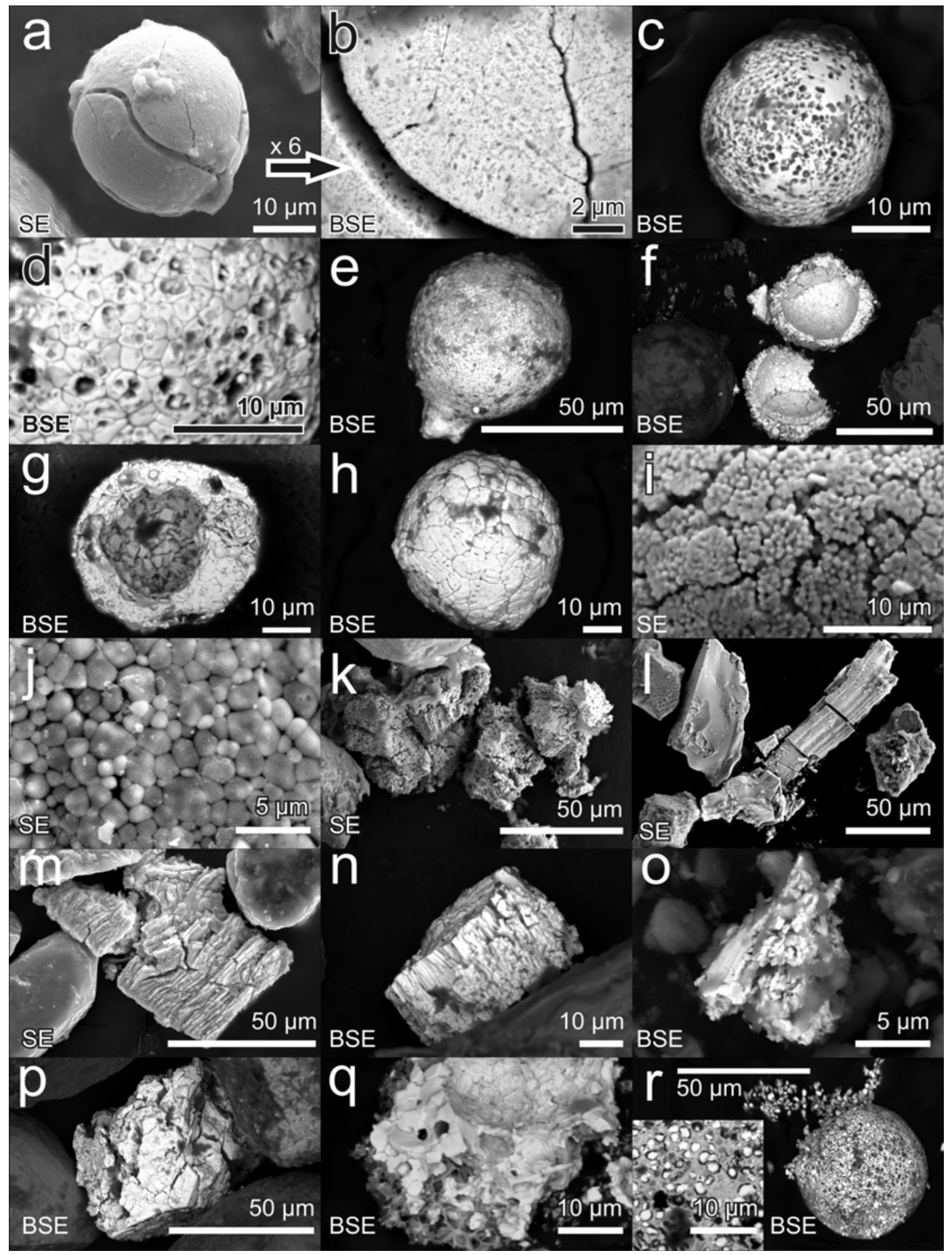

FIG. 3. SEM images of uraniferous particles from dust and soil samples, showing a range of primary morphologies and textures, which are discussed in the text. Images from soils samples are as follows: $c, d, k, n, q$ and $r$. 
aggregates of $\mu \mathrm{m}$-scale diameter particulates are also seen (Appendix 2.5), similar to those from Chernobyl emissions (Salbu et al., 1994). Fluffy aggregates of fine particulates are reasonably common in the samples (Fig. $3 k$ and Appendix 2.5 ), and may have been produced by vapour condensation, nucleation and coagulation of particulates in the NLI furnace.

Morphologies that resemble metal shavings have been observed. Fig. $3 l$ shows a small uraniferous rod that has fractured during sample preparation. This brittle behaviour suggests that it is oxidized throughout. The foliated texture displayed in Fig. $3 m$ is typical of the combustion of DU metal ammunition between 973-1173 K (Elder and Tinkle, 1980).

In addition to spheres, the appendices in Parkhurst et al. (2004) include SEM micrographs of aggregates and some bladed crystal textures similar to Fig. $3 n$ (specifically fig. D.2, or fig. 4 in Krupka et al., 2009). A mixed morphology, partly ordered and polycrystalline, partly a disordered aggregate, similar to Fig. $3 o$, is also presented there (also in fig. 6, Krupka et al., 2009).

The block of uranium oxide in image Fig. $3 p$ shows multiple fractures, similar to expansion textures resulting from the oxidation of $\mathrm{UO}_{2}$ to $\mathrm{U}_{3} \mathrm{O}_{8}$ (McEachern and Taylor, 1998), which could have occurred in the furnace environment. Only one such example was identified.

An unusual texture of DU oxide $(+\mathrm{Ti})$ on an $\mathrm{Al}$ /alumina 'honeycomb' mesh $( \pm \mathrm{Na})$ in image Fig. 3q, may have been formed by the partial dissolution (in a wet soil environment) of a U-Al liquid phase sintered product, or possibly $U$ precipitation on a refractory material. Alternatively, it is similar to catalysts patented by Mabilon et al. (1991) but on a microscopic scale, which may have been an experimental product of NLI. Figure $3 r$ shows a sphere that comprises $\sim 60 \%$ uranium oxide crystals $(0.3-3 \mu \mathrm{m}$ diameter $)$ in an $\mathrm{Fe}$ or Fe-oxide matrix.

More than 100 uranium oxide spheres were identified in the 20-64 $\mu \mathrm{m}$ geometric diameter range (median $37 \mu \mathrm{m}$, approximate unimodal normal particle size distribution, see Appendix 2.8 for histogram). The concentration techniques employed limit this size range, especially for the lower end. These spheres are typically polycrystalline with equiaxial grains, $\sim 1 \mu \mathrm{m}$ diameter (estimated size range $0.3-12 \mu \mathrm{m}$ ).

Of those sectioned $(n=45), 42 \%$ were hollow and another $42 \%$ included cavities; only $16 \%$ appeared solid. Of those sectioned, $60 \%$, appeared to comprise $\mathrm{U}$ and $\mathrm{O}$ only. Minor EDXA peaks from $\mathrm{Ti}$ were detected in $27 \%$ of the remainder, $\mathrm{Al}$ in $20 \%$ and other elements in only $9 \%$ (LoD $\sim 1$ wt.\%). Analysis of the cleaned cross-sections avoided the surface contaminants seen on the whole particles.

\section{Formation of uranium oxide spheres}

Spherical particles were deliberately picked for the XAS analyses, because they can be recognized under an optical microscope. This distinctive morphology is observed from the debris of DU munitions impacting with armoured targets (dominant morphology, Patrick and Cornette, 1978; common morphology, Parkhurst et al., 2004; Krupka et al., 2009) and less commonly in contaminated dusts and soils from the Colonie case-study. The coarse size of these spheres distinguishes them from the $1-2 \mu \mathrm{m}$ diameter spherical uraniferous particles formed by the oxidation and hydrolysis of $\mathrm{UF}_{6}$ escaping from enrichment plants, which are the focus of nuclear forensic analyses (Stebelkov, 2005; Kips et al., 2007).

A number of experimental studies have produced similar spheres. Jones et al. (1964) produced $\mathrm{UO}_{2}$ microspheres by passing metaloxide through an inductively coupled plasma torch (stoichiometric $\mathrm{UO}_{2}$ microspheres $<50 \mu \mathrm{m}$ diameter were red in colour, some of the spheres were hollow). Surya Narayana et al. (1994) electrically heated $\mathrm{UO}_{2}$ pellets to a peak temperature of $3773 \mathrm{~K}$, producing aggregates of fine $\mathrm{U}_{3} \mathrm{O}_{8}$ particulates (attributed to vapour condensation) as well as larger low-solubility $\mathrm{UO}_{2}$ spheres ( $\sim 4 \mathrm{~m}$ diameter). Carter and Stewart (1970) produced $\mathrm{Pu}$ and $\mathrm{U}$ spheres in the $0.1-1 \mathrm{~mm}$ range, using exploding metal wire and freefall droplets (melted and ignited at $933 \mathrm{~K}$ ). They displayed a range of colours (white, yellow, orange, brown, black) and textures (reticulation, dimpling, striations, glassy). Sparks from shattering freefall droplets produced spheres, often hollow. This was interpreted as rapid volatilization and emission of $U$ from combusting molten metal/oxide droplets.

Martz and Hashke (1998) present a conceptual model (supported by theoretical modelling and experimental data) for the combustive heating of $\mathrm{Pu}$ droplets. Following melting and ignition, this proceeds by autothermic oxidation and achieves very high internal temperatures sufficient to 
volatilize and vent $\mathrm{Pu}$, leaving fragmented and hollow $\mathrm{PuO}_{2}$ shells. Uranium is also a pyrophoric material and $\mathrm{UO}_{2}$ has a similar heat of formation as $\mathrm{PuO}_{2}$ and might be expected to behave in a similar way.

Peak burning temperatures for small chunks of $\mathrm{U}$ metal in air reach $1773 \mathrm{~K}$ (Baker $\mathrm{Jr}$ et al., 1966), exceeding the U melting point of $1405 \mathrm{~K}$ (Katz and Seaborg, 1957). We propose that the observed hollow uranium oxide spheres were formed by the ejection of small liquid-metal droplets, the temperatures of which were much higher than the $U$ ignition temperature of 563-973 K (Baker Jr et al., 1966). Autothermic oxidation raised their internal temperature, sufficient in many instances to volatilize and vent the contents (4091 K for U metal, Katz and Seaborg, 1957; $3815 \mathrm{~K}$ for uranium dioxide, INSC, 2008). This process would be observed as bright sparks spitting from the furnace and sometimes exploding. Presumably, the vapour condensed and nucleated to form ultrafine particulates and agglomerates. The stability of $\mathrm{U}_{3} \mathrm{O}_{8}$ was exceeded (1878 K, Taylor, 2005); if cooled quickly, $\mathrm{UO}_{2+x}$ is the expected phase (freezing at $\sim 3120 \mathrm{~K}$, INSC, 2008), but if held at intermediate temperatures this may oxidize further.

Powder metallurgy is a processing technology, commonly used to produce complex shaped metal articles directly, by compressing and sintering metal powders (German, 1994). The extreme reactivity of $U$ metal may appear to make this unattractive. However, U metal powders have been processed by reduction of oxides and hydride-dehydride conversion (Bellamy and Buddery, 1952; Clark et al., 1998). A contemporary account of $U$ metallurgy is given in Meerson (1960).

A few of the particles identified are comprised of $\mu \mathrm{m}$ diameter uranium oxide grains with triplejunctions, a texture consistent with compressed, but not fully sintered powders (Fig. $3 j$ ). The texture in Fig. $3 q$ could be explained as dissolution of crystalline uranium oxides from a liquidphase sintered powder, exposing a second alumina phase.

There is some evidence that $U$ powder metallurgy, which can produce uranium oxide spheres, may have been employed at NLI. However, the observed cavities and the size range of the spheres are not consistent with the powder metallurgy techniques typically used for $\mathrm{U}$. There is strong evidence that the spheres were produced by oxidation of melt droplets.

\section{Summary of SEM work}

Electron microscopy reveals a range of morphologies and textures. Many of the uraniferous particles are polycrystalline and some are spherical. The uranium oxide spheres are attributed to a specific process, i.e. the autothermic oxidation of melt droplets. Similar spheres are formed by DU munitions impacting armoured targets. All of the particles presented in Fig. 3 and most of those identified by this study have primary morphologies, attributed to specific processes at NLI. Some of the particles show evidence of minor dissolution, including a few with evidence of corrosion pitting, a process that enhances oxidation and dissolution. Readily identifiable evidence of secondary particles, precipitates of $U$, in these samples (e.g. schoepite/metaschoepite in Appendix 2.5) is scarce.

In summary, electron microscopy reveals that dust and soil samples from Colonie are contaminated by primary uranium oxide particulates and that these have survived more than $25 \mathrm{y}$ of exposure in the terrestrial environment.

$\mu X A S$

\section{$\mu X A N E S$}

$\mu X A N E S$ for the standards showed the expected increase in edge position (point of inflection) for higher oxidation states, presented in Appendix 1.4. However, the estimates for the samples were typically less than the $\mathrm{UO}_{2}$ standard and do not appear reliable.

\section{$\mu E X A F S$}

$\mu \mathrm{EXAFS}$ spectra were isolated for each point analysis, where possible from the average of replicate absorption profiles. To correct for the variable edge estimates used, the $\mu \mathrm{EXAFS}$ spectra were re-aligned for the first peak to the $\mathrm{UO}_{2}$ standard $(\mathrm{k}=1.39)$, via energy space, $\mu(\mathrm{E})$. The $\mu$ EXAFS are presented as k-squared weighted chi against $\mathrm{k}, \chi \cdot \mathrm{k}^{2}(\mathrm{k})$, in Figs 2 and 4 (and Appendix 1.2). Theoretical modelling of the standard spectra produced reasonable fits for 2 or 3 scattering shells, including multiple scattering paths (Fig. 2).

This study focuses on the second dominant oscillation, because the first oscillation includes the 'white-line' and is overly sensitive to spline fitting, and the data are noisy for the third and subsequent oscillations. For $\mathrm{UO}_{2}$, the second 


\section{MORPHOLOGIES AND COMPOSITIONS OF DU PARTICLES}

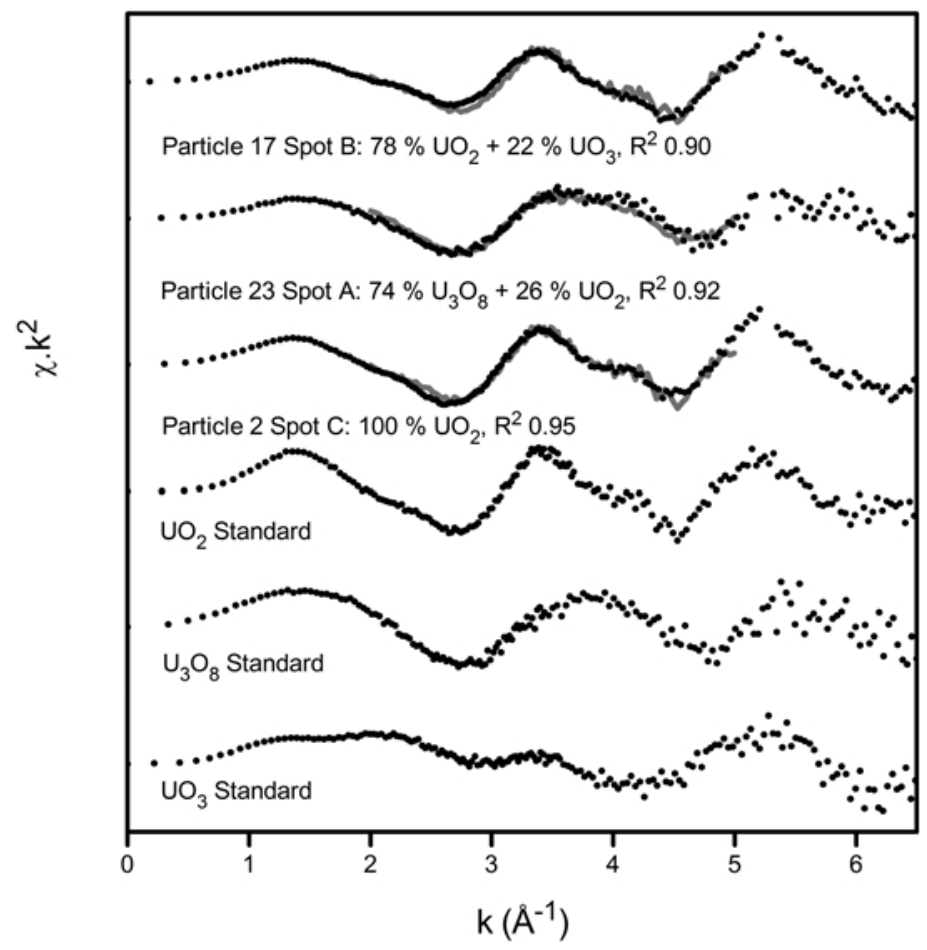

FIG. 4. $\mu$ EXAFS spectra for 3 standards and 3 selected sample spectra from the dust sample. Least-squares fitting of the standards to the sample spectra achieved good adjusted- $\mathrm{R}^{2}$ values $(>0.75$, adjusted for degrees of freedom).

Fitting parameter uncertainties $\sim \pm 10 \%$ for these spectra.

dominant oscillation has a pronounced asymmetric shape and can be approximated by the contributions from the first $\mathrm{O}$ and $\mathrm{U}$ shells. In contrast, the second oscillation for $\mathrm{U}_{3} \mathrm{O}_{8}$ is approximately symmetrical and slightly extended (from a closer $\mathrm{O}$ shell). The ' $\mathrm{UO}_{3}$ ' spectrum is characterized by a distinctive 'shoulder' on the first peak, similar to that modelled by multiple scattering along a uranyl group (Hudson et al., 1995). We applied linear combination leastsquares fitting, using the three standard spectra, to each of the sample spectra, in the region $\mathrm{k}=$ $2-5 \AA^{-1}$, which covers these characteristic features.

Three selected sample spectra are compared with the standards in Fig. 4, the complete set of 42 sample spectra can be found in Appendix 1. The compositions from the spot analyses are presented in Fig. 5.

By using a microfocus beamline, it was possible to analyse different parts of individual particles, but no clear differences in composition between rim and core were observed. With a $3.5 \mu \mathrm{m}$ beam, it was not expected to detect thin surface films of higher oxides. The spatial resolution of the spot analyses averages across several crystals and grain boundaries within the polycrystalline particles. Due to the sample geometry in our experiments, it would not be possible to create a symmetrical cross-sectional profile or map from individual particles, as the leading edge is shielded by the body of the particle. Furthermore, when the edge of the particle is approached, absorption is minimized and the spectra become increasingly noisy. Physical rotation of the particle, particle sectioning and longer counting times for edge analyses would be required to overcome these issues.

\section{Discussion}

Osán et al. (1997) utilized a least squares fitting approach for the XANES (for As, to $40 \mathrm{eV}$ above 


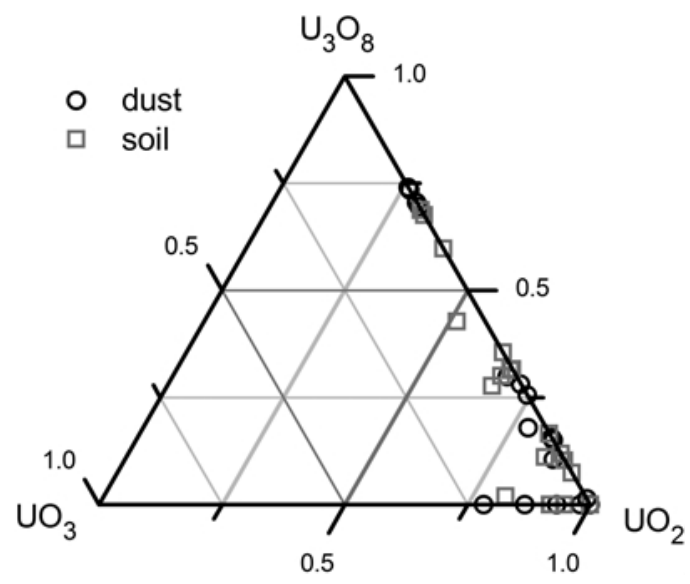

FIG. 5. Ternary diagram of the estimated compositions of microscopic uranium oxide spheres from $\mu$ EXAFS spot analyses. The compositions are dominated by $\mathrm{UO}_{2}$, with variable amounts of $\mathrm{U}_{3} \mathrm{O}_{8}$. Fitting parameter uncertainties are typically $\pm 5-15 \%$ of total. $\mathrm{UO}_{3}$ is only significant $(2 \sigma)$ for 3 spectra. Minor components, less than $10 \%$, should be treated with caution. Spectra from 7 soil grains and 7 dust grains show a similar distribution of compositions. The fitting data are tabulated in Appendix 1.3.

the $K$-edge), fitting white-line, 'multiple-scattering' and edge curves to the spectra. They argued that since the white-line overlaps the true absorption edge, it is not sufficient to study this alone. Török et al. (2004) argued that this method is superior to the inflection points measured by Salbu et al. (2003).

The edge positions for our data did not prove to be reliable indicators of composition. Whether this is due to instrumental drift or some other factor is uncertain. Typical EXAFS analyses span several oscillations to higher $\mathrm{k}$ values and utilize the radial function to resolve contributions from individual scattering shells. The amplitude of EXAFS oscillations diminishes towards higher $\mathrm{k}$ values; noise therefore becomes an inherent issue. This is especially true for microfocus spectroscopy, which excites a small sample volume with a reduced X-ray intensity. Long counting times would be required to improve spectra quality, but this would limit the number of samples analysed, further compromising representativity. Therefore, sample spectra were only acquired to $7 \AA^{-1}$.

This study employed an alternative strategy, least-squares fitting for a limited portion of the $\mu$ EXAFS spectra, including the second oscillation and the uranyl shoulder of the $\mathrm{UO}_{3}$ standard, in the region $\mathrm{k}=2-5 \AA^{-1}$. Adjusted $\mathrm{R}^{2}$ values of $\sim 0.9$ and examination of the residuals, suggest that the fits are generally good. The uncertainty of the fitting parameters is typically in the range of $\pm 5-15 \%$, precluding detailed comparisons between individual spot analyses. On a generalized and qualitative basis, the spot analyses are consistent across individual spheres.

$\mathrm{UO}_{2}$ and $\mathrm{U}_{3} \mathrm{O}_{8}$ oxides are the most commonly reported combustive products of DU munitions in environmental samples (Table 1) and the common phases identified for these samples. This study found a dominance of $\mathrm{UO}_{2}$, with variable amounts of $\mathrm{U}_{3} \mathrm{O}_{8}$. The model of autothermic oxidation and venting from melt droplets predicts core temperatures that exceed the stability of $\mathrm{U}_{3} \mathrm{O}_{8}$, freezing as $\mathrm{UO}_{2}$, which may then (slowly) re-oxidize to $\mathrm{U}_{3} \mathrm{O}_{8}$ at intermediate temperatures. These data are compatible with this model.

It should be noted that these $\mu$ EXAFS spectra and the cited XAS studies, do not resolve stoichiometric $\mathrm{UO}_{2}$ from the more than likely hyperstoichiometric uranium oxides and it would be preferable to state $\mathrm{UO}_{2+\mathrm{x}}$. Allen et al. (1985) and Jones et al. (1986) demonstrated the subtle differences in the EXAFS spectra of the cubic uranium oxides $\left(\mathrm{UO}_{2}, \mathrm{U}_{4} \mathrm{O}_{9}\right.$ and $\left.\beta-\mathrm{U}_{3} \mathrm{O}_{7}\right)$; resolving these species from each other for environmental particles is probably beyond the scope of $\mu$ XAS.

Uranyl species, represented by the $\mathrm{UO}_{3}$ standard, appear to be rare in these spheres. In contrast, uraniferous particles analysed in a core sample from a reservoir sediment (wet environment), appear to include metaschoepite (Arnason et al., 2008). These reservoir sediments accumulated U compared to nearby soils and it appears likely that any uranyl species precipitated from watershed runoff, which includes effluent discharged from the NLI site.

Particulates from DU munitions impacting armour, sampled directly from aerosol and including morphologically similar spheres, are predominantly $\mathrm{U}_{3} \mathrm{O}_{8}$ and $\mathrm{U}_{4} \mathrm{O}_{9}$ in composition with no $\mathrm{UO}_{2}$ detected by XRD (Parkhurst et al., 2004; Krupka et al., 2009). However, in XRD, there are spectral overlaps between $\mathrm{U}_{3} \mathrm{O}_{8}$ and $\mathrm{UO}_{3}$ and also between $\mathrm{U}_{4} \mathrm{O}_{9}$ and $\mathrm{UO}_{2}$, limiting the detection of minor $\mathrm{UO}_{3}$ and $\mathrm{UO}_{2}$ (Krupka et al., 2009). Mitchell and Sunder (2004) identified $\mathrm{U}_{3} \mathrm{O}_{7}$ as a common phase from DU munitions impacting armoured targets, along with $\mathrm{U}_{3} \mathrm{O}_{8}$ and minor 
$\mathrm{UO}_{2+\mathrm{x}}$. As discussed previously, the cubic uranium oxide phases are also difficult to resolve for environmental particle samples using $\mu \mathrm{XAS}$. A discussion of alternative analytical techniques for $\mathrm{U}$ speciation is beyond the scope of this paper, but XPS (e.g. Schueneman et al., 2003) and $\mu-$ Raman spectroscopy (e.g. Allen et al., 1987) could be considered for future studies of this material.

The apparent differences in compositions for the DU munitions aerosol may be due to the selection of a specific morphology and size-range for this study and the inclusion of others in the bulk aerosol samples. The $\mathrm{UO}_{2}$ rich particles are also more likely to survive environmental exposure intact, to the point of selective picking for analysis.

This study, as with those of Török et al. (2004) and Salbu et al. (2003), analysed a limited number of particles, which may not be fully representative of the environmental samples. We also acknowledge that these particles were selected by morphology from a specific size-range. It is therefore not necessarily appropriate to extrapolate these findings to respirable particulates. However, the continued excretion of anthropogenic isotope ratios by workers and some residents, more than 20 y after exposure (Parrish et al., 2008), suggests that the inhaled particulates were also low-solubility phases (e.g. $\mathrm{UO}_{2}$ and/or $\mathrm{U}_{3} \mathrm{O}_{8}$ ).

\section{Conclusions}

This initial study of the Colonie particles shows that mixed $\mathrm{UO}_{2+x}$ and $\mathrm{U}_{3} \mathrm{O}_{8}$ micro-spheres survive in the terrestrial environment (soils and dusts) for at least $25 \mathrm{y}$. The $U$ from these lowsolubility phases, dominated by $\mathrm{U}^{4+}$, is less bioaccessible and less mobile than uranyl species (e.g. $\mathrm{UO}_{3}$ ). Higher solubility, uranyl species $\left(\mathrm{U}^{6+}\right)$ are a rare and minor component of the analysed particles.

A range of primary particle morphologies, as emitted from NLI, have been identified and survive to the present time. The morphologies of the contaminant uraniferous particles include microscopic uranium oxide spheres that are similar to those produced from DU munitions impacting armoured targets. This further supports the case for using Colonie as a realistic analogue for battlefield contamination by DU. Morphological investigation and compositional analyses of uraniferous fine particulates in these samples are recommended for further work.

\section{Acknowledgements}

This research was sponsored by the British Geological Survey (NERC) and the NERC Isotope Geosciences Laboratory (NIGL). We are grateful for support from The Diamond Light Source (STFC \& Wellcome Trust) and from the Advanced Microscopy Centre (University of Leicester).

The authors thank the following for their assistance and technical advice: Mark Allen, John Arnason, Jenny Bearcock, John Bridges, Hitesh Changela, Graham Clark, Quentin Crowley, Laura Howell, Antoni Milodowski, Mike Norry, Barry Smith, Rob Wilson and Adrian Woods. We also thank the residents of Colonie who allowed us access to sampling sites and the members of CCNL for their cooperation.

Simon Chenery and Simon Kemp publish with the permission of the director of the British Geological Survey.

Appendices (online deposited material) Appendix 1 - XAS spectra, fitting data and XRD of standards

Appendix 2 - Supplementary SEM images

Available from: www.minersoc.org/pages/ e_journals/dep_mat_mm.html

\section{References}

Allen, G.C. and Tempest, P.A. (1986) Ordered defects in the oxides of uranium. Proceedings of the Royal Society of London, Series A: Mathematical and Physical Sciences, 406, 325-344.

Allen, G.C., Tempest, P.A., Garner, C.D., Ross, I. and Jones, D.J. (1985) EXAFS: A new approach to the structure of uranium oxides. Journal of Physical Chemistry, 89, 1334-1336.

Allen, G.C., Butler, I.S. and Anh Tuan, N. (1987) Characterisation of uranium oxides by micro-Raman spectroscopy. Journal of Nuclear Materials, 144, $17-19$.

Anderson, J.S., Roberts, L.E.J. and Harper, E.A. (1955) The oxides of uranium. Part VII. The oxidation of uranium dioxide. Journal of the Chemical Society (Resumed), 3946-3959.

Ansoborlo, E., Chazel, V., Henge-Napoli, M.H., Pihet, P., Rannou, A., Bailey, M.R. and Stradling, N. (2002) Determination of the physical and chemical properties, biokinetics and dose coefficients of uranium compounds handled during nuclear fuel fabrication in France. Health Physics, 82, 279-289.

Arnason, J.G. and Fletcher, B.A. (2003) A 40+ year record of $\mathrm{Cd}, \mathrm{Hg}, \mathrm{Pb}$ and $\mathrm{U}$ deposition in sediments 


\section{N. S. LLOYD ET AL.}

of Patroon reservoir, Albany county, NY, USA. Environmental Pollution, 123, 383-391.

Arnason, J.G., Lloyd, N.S., Parrish, R.R., Tang, Y. and Reeder, R.J. (2008) Oxidation of uranium oxide aerosol particles in the near-surface environment. Geochimica et Cosmochimica Acta, 72, A33.

ATSDR. (2004) Health Consultation: Colonie Site. Agency for Toxic Substances and Disease Registry, Atlanta, USA.

Baker Jr, L., Schnizlein, J.G. and Bingle, J.D. (1966) The ignition of uranium. Journal of Nuclear Materials, 20, 22-38.

Bellamy, R.G. and Buddery, J.H. (1952) The Production of Uranium Powder by the Uranium DioxideMagnesium Route. AWRE, Harwell, UK.

Berry, J.P., Zhang, L., Galle, P., Ansoborlo, E., HengéNapoli, M.H. and Donnadieu-Claraz, M. (1997) Role of alveolar macrophage lysosomes in metal detoxification. Microscopy Research and Technique, 36, 313-323.

Bleise, A., Danesi, P.R. and Burkart, W. (2003) Properties, use and health effects of depleted uranium (DU): A general overview. Journal of Environmental Radioactivity, 64, 93-112.

Carter, R.F. and Stewart, K. (1970) On the oxide fume formed by the combustion of plutonium and uranium. Inhaled particles, 2, 819-838.

Clark, C.R., Meyer, M.K. and Strauss, J.T. (1998) Fuel powder production from ductile uranium alloys. International Meeting on Reduced Enrichment for Research and Test Reactors, Sao Paulo, Brazil.

Dietz, L.A. (1980) Investigation of excess alpha activity observed in recent air filter collections and other environmental samples, (CHEM-434-LAD). Knolls Atomic Power Laboratory, General Electric Company, Schenectady, New York, USA.

Eidson, A.F. (1994) The effect of solubility on inhaled uranium compound clearance: A review. Health Physics, 67, 1-14.

Elder, J.C. and Tinkle, M.C. (1980) Oxidation of depleted uranium penetrators and aerosol dispersal at high temperatures, (LA-8610-MS). Los Alamos Scientific Laboratory, New Mexico, USA.

Finch, R.J. and Ewing, R.C. (1992) Corrosion of uraninite under oxidizing conditions. Journal of Nuclear Materials, 190, 133-156.

Fletcher, D.A., McMeeking, R.F. and Parkin, D. (1996) The United Kingdom chemical database service. Journal of Chemical Information and Computer Sciences, 36, 746-749.

Frankel, G.S. (1998) Pitting corrosion of metals: A review of the critical factors. Journal of the Electrochemical Society, 145, 2186-2198.

German, R.M. (1994) Powder Metallurgy Science. Metal Powder Industries Federation, Princeton, New Jersey, USA.
Guilmette, R.A. and Cheng, Y.S. (2009) Physicochemical characterization of Capstone depleted uranium aerosols IV: In vitro solubility analysis. Health Physics, 96, 292-305.

Hopson, J.W., Hantel, L.W. and Sandtstrom, D.J. (1973) Evaluation of depleted-uranium alloys for use in armor-piercing projectiles (U), (LA-5238). Los Alamos Scientific Laboratory of the University of California, USA.

Hudson, E.A., Rehr, J.J. and Bucher, J.J. (1995) Multiple-scattering calculations of the uranium $\mathrm{L}_{3^{-}}$ edge X-ray-absorption near-edge structure. Physical Review B, 52, 13815-13826.

ICRP. (1995) Age-dependent doses to members of the public from intake of radionuclides: Part 4 inhalation dose coefficients. Annals of the ICRP, 25.

INSC. (2008) INSC Material Properties Database. International Nuclear Safety Center, Argonne National Laboratory for US Department of Energy, Illinois, USA.

Jeter, H.W. and Eagleson, D.M. (1980) A Survey of Uranium in Soils surrounding the NL bearings Plant, (IWL-9488-461). Teledyne Isotopes, Westwood, New Jersey, USA.

Jones, D.J., Roziere, J., Allen, G.C. and Tempest, P.A. (1986) The structural determination of fluorite-type oxygen excess uranium oxides using EXAFS spectroscopy. The Journal of Chemical Physics, 84, 6075-6082.

Jones, L.V., Ofte, D., Phipps, K.D. and Tucker, P.A. (1964) Preparation and properties of plutoniumbearing oxide particulates. Industrial and Engineering Chemistry Product Research and Development, 3, 78-82.

Kashparov, V.A., Ahamdach, N., Zvarich, S.I., Yoschenko, V.I., Maloshtan, I.M. and Dewiere, L. (2004) Kinetics of dissolution of Chernobyl fuel particles in soil in natural conditions. Journal of Environmental Radioactivity, 72, 335-353.

Katz, J.J. and Seaborg, G.T. (1957) The Chemistry of the Actinide Elements. Methuen \& Co. Ltd (John Wiley \& Sons Inc., NY), London.

Kips, R., Leenaers, A., Tamborini, G., Betti, M., Van Den Berghe, S., Wellum, R. and Taylor, P. (2007) Characterization of uranium particles produced by hydrolysis of $\mathrm{UF}_{6}$ using SEM and SIMS. Microscopy and Microanalysis, 13, 156-164.

Koningsberger, D.C. and Prins, R., (editors). (1988) X-ray Absorption; Principles, Applications, Techniques of EXAFS, SEXAFS and XANES. John Wiley \& Sons, Chichester, UK.

Krupka, K.M., Parkhurst, M.A., Gold, K., Arey, B.W., Jenson, E.D. and Guilmette, R.A. (2009) Physicochemical characterization of Capstone depleted uranium aerosols III: Morphologic and chemical oxide analyses. Health Physics, 96, 
$276-291$.

Langmuir, D. (1997) Aqueous Environmental Geochemistry. Prentice-Hall International, London.

Lind, O.C., Salbu, B., Janssens, K., Proost, K., GarcíaLeón, M. and García-Tenorio, R. (2007) Characterization of $\mathrm{U} / \mathrm{Pu}$ particles originating from the nuclear weapon accidents at Palomares, Spain, 1966 and Thule, Greenland, 1968. Science of the Total Environment, 376, 294-305.

Lloyd, N.S., Parrish, R.R., Chenery, S.R. and Arnason, J.G. (2008) The environmental fate of depleted uranium particulate after 25 years. Geochimica et Cosmochimica Acta, 72, A566.

Lloyd, N.S., Parrish, R.R., Horstwood, M.S.A. and Chenery, S.R.N. (2009) Precise and accurate isotopic analysis of microscopic uranium-oxide grains using LA-MC-ICP-MS. Journal of Analytical Atomic Spectrometry, 24, 752-758.

Lo, D., Fleischer, R.L., Albert, E.A. and Arnason, J.G. (2006) Location, identification and size distribution of depleted uranium grains in reservoir sediments. Journal of Environmental Radioactivity, 89, 240-248.

Mabilon, G., Durand, D., Courty, P. and Prigent, M. (1991) Multifunctional catalyst for treating exhaust fumes from internal combustion engines, containing uranium, at least one uranium promotor and at least one precious metal and its preparation. US Patent 5051392. Institut Francais Du Petrole, Rueil Malmaison, France.

Martz, J.C. and Haschke, J.M. (1998) A mechanism for combustive heating and explosive dispersal of plutonium. Journal of Alloys and Compounds, 266, 90-103.

Matzke, H. (1999) Range, energy loss, energy straggling and damage production for $\alpha$-particles in uranium dioxide. Journal of Nuclear Materials, 270, 49-54.

McEachern, R.J. and Taylor, P. (1998) A review of the oxidation of uranium dioxide at temperatures below $400^{\circ} \mathrm{C}$. Journal of Nuclear Materials, 254, 87-121.

Meerson, G.A. (1960) Aspects of the metallurgy of uranium and constructional metals. The Soviet Journal of Atomic Energy, 6, 69-72.

Mitchel, R.E.J. and Sunder, S. (2004) Depleted uranium dust from fired munitions: Physical, chemical and biological properties. Health Physics, 87, 57-67.

Mosselmans, J.F.W., Quinn, P.D., Rosell, J.R., Atkinson, K.D., Dent, A.J., Cavill, S.I., Hodson, M.E., Kirk, C.A. and Schofield, P.F. (2008) The first environmental science experiments on the new microfocus spectroscopy beamline at Diamond. Mineralogical Magazine, 72, 197-200.

Osán, J., Török, B., Török, S. and Jones, K.W. (1997) Study of chemical state of toxic metals during the life cycle of fly ash using X-ray absorption near-edge structure. X-ray Spectrometry, 26, 37-44.
Parkhurst, M.A., Daxon, E.G., Lodde, G.M., Szrom, F., Guilmette, R.A., Roszell, L.M., Falo, G.A. and McKee, C.B. (2004) Capstone aerosols: Depleted uranium aerosol doses and risks. Prepared for the U.S. Army, Battelle Press, Columbus, Ohio, USA.

Parrish, R.R., Horstwood, M., Arnason, J.G., Chenery, S., Brewer, T., Lloyd, N.S. and Carpenter, D.O. (2008) Depleted uranium contamination by inhalation exposure and its detection after $\sim 20$ years: Implications for human health assessment. Science of the Total Environment, 390, 58-68.

Patrick, M.A. and Cornette, J.C. (1978) Morphological Characteristics of Particulate Material formed from High Velocity Impact of Depleted Uranium Projectiles with Armor Targets, (AFATL-TR-78117). U.S. Air Force Armament Laboratory.

Roth, O. and Jonsson, M. (2008) Oxidation of $\mathrm{UO}_{2(\mathrm{~s})}$ in aqueous solution. Central European Journal of Chemistry, 6, 1-14.

Salbu, B., Krekling, T., Oughton, D.H., Østby, G., Kashparov, V.A., Brand, T.L. and Day, J.P. (1994) Hot particles in accidental releases from Chernobyl and Windscale nuclear installations. The Analyst, 119, 125-130.

Salbu, B., Krekling, T., Lind, O.C., Oughton, D.H., Drakopoulos, M., Simionovici, A., Snigireva, I., Snigirev, A., Weitkamp, T., Adams, F., Janssens, K. and Kashparov, V.A. (2001) High energy X-ray microscopy for characterisation of fuel particles. Nuclear Instruments and Methods in Physics Research Section A: Accelerators, Spectrometers, Detectors and Associated Equipment, 467-468, 1249-1252.

Salbu, B., Janssens, K., Lind, O.C., Proost, K. and Danesi, P.R. (2003) Oxidation states of uranium in DU particles from Kosovo. Journal of Environmental Radioactivity, 64, 167-173.

Salbu, B., Janssens, K., Lind, O.C., Proost, K., Gijsels, L. and Danesi, P.R. (2005) Oxidation states of uranium in depleted uranium particles from Kuwait. Journal of Environmental Radioactivity, 78, $125-135$.

Schueneman, R.A., Khaskelis, A.I., Eastwood, D., van Ooij, W.J. and Burggraf, L.W. (2003) Uranium oxide weathering: Spectroscopy and kinetics. Journal of Nuclear Materials, 323, 8-17.

Stebelkov, V. (2005) Informativeness of morphology analysis of uranium microparticles from industrial dust at nuclear plants. Proceedings of the GLOBAL 2005 Conference, Tsukuba, Japan.

Surya Narayana, D.S., Sundararajan, A.R. and Harvey, J. (1994) Characterization of uranium oxide aerosols. Journal of Aerosol Science, 25, 909-922.

Taylor, P. (2005) Thermodynamic and kinetic aspects of $\mathrm{UO}_{2}$ fuel oxidation in air at 400-2000 K. Journal of Nuclear Materials, 344, 206-212. 
Tenderholt, A., Hedman, B. and Hodgson, K.O. (2007) Pyspline: A modern, cross-platform program for the processing of raw averaged XAS edge and EXAFS data. Pp. 105-107 in: Conference Proceedings, 882, American Institute of Physics. New York, USA.

The Royal Society. (2001) The Health Hazards of Depleted Uranium Munitions, part I. The Royal Society, London.

The Royal Society. (2002) The Health Hazards of Depleted Uranium Munitions, part II. The Royal Society, London.

Tomic, S., Searle, B.G., Wander, A., Harrison, N.M., Dent, A.J., Mosselmans, J.F.W. and Inglesfield, J.E. (2005) New tools for the analysis of EXAFS: The DL_EXCURV package, (DL-TR-2005-001). Council for the Central Laboratory of the Research Councils, UK.
Török, S., Osán, J., Vincze, L., Kurunczi, S., Tamborini, G. and Betti, M. (2004) Characterization and speciation of depleted uranium in individual soil particles using microanalytical methods. Spectrochimica Acta - Part B Atomic Spectroscopy, 59, 689-699.

Torrero, M.E., Casas, I., de Pablo, J., Duro, L. and Bruno, J. (1998) Oxidative dissolution mechanism of uranium dioxide at $25^{\circ} \mathrm{C}$. Mineralogical Magazine, 62A, 1529-1530.

Wadsten, T. (1977) Oxidation of polycrystalline uranium dioxide in air at room temperature. Journal of Nuclear Materials, 64, 315.

Wang, R. and Katayama, Y.B. (1982) Dissolution mechanisms for $\mathrm{UO}_{2}$ and spent fuel. Nuclear and Chemical Waste Management, 3, 83-90. 